\title{
TEGANGAN DAN REGANGAN DINAMIS PERKERASAN SEMI FLEKSIBEL DENGAN MODIFIKASI REOLOGI ASPAL DAN SUBSTITUSI ZIOLIT PADA SEMEN MORTAR
}

\author{
Hamzani $^{(1)}$, Munirwansyah ${ }^{2)}$, Sugiarto $^{3)}$, Muttaqin Hasan ${ }^{4)}$ \\ Jurusan Teknik SipilUniversitas Malikussaleh, Lhokseumawe, Indonesial) \\ Jurusan Teknik SipilUniversitas Syiah Kuala, Banda Aceh, Indonesia ${ }^{2,3,4)}$ \\ Email: hamzani@unimal.ac.id ${ }^{1)}$,nir_geotechnical@unsyiah.ac.id ${ }^{2}$, \\ sugiarto@unsyiah.ac.id ${ }^{3)}$, muttaqin@unsyiah.ac.id $^{4}$
}

DOI: http://dx.doi.org/10.29103/tj.v11i1.405

(Received: November 2020 / Revised: December 2020 / Accepted: January 2021)

\begin{abstract}
Abstrak
Ketahanan struktur perkerasan akibat timbulnya tegangan dan regangan menyebabkan retak awal saat terjadinya deformasi permanent sehingga kegagalan perkerasan akibat kelelahan umur tidak dihindarkan. Fenomena tersebut dapat dikurangi dengan perkerasan yang memiliki cukup kekakuan, kelenturan. Modifikasi material dilakukan untuk meningkatkan nilai kekakuan dan kelenturan campuran dengan menggunakan jenis campuran,gradasi, dan modifikasi aspal yang tepat sebagai usaha pengembangan campuran perkerasan beraspal. Tujuan dari penelitian ini mempelajari tegangan dan regangan tarik campuran PSF terhadap beban berulang dengan tambahan WTR dan menggunakan ziolit alam sebagai pengganti sebagian semen untuk mortar yang dinjeksi ke dalam rongga aspal porous. Desain campuran aspal berpori dimulai dengan penentuan proporsi aspal optimal dengan agregat bergradasi terbuka sebagaimana ditentukan dalam sepesifikasi (AAPA) 2004. Uji Marshall dilakukan untuk mengetahui spesifikasi yang disyaratkan dan dilanjutkan dengan uji specimen yang telah diinjeksi mortar semen dengan pengujian lentur metode pembebanan empat titik untuk evaluasi tegangan dan regangan tarik. Nilai tegangan dan regangan dinamis dianalisis pada setiap variasi ziolit dalam mortar semen. Substitusi ziolit alam pada semen mortar dapat mempengaruhi tegangan dan regangan dinamis campuran PSF, di mana semakin besar komposisi ziolit dalam semen mortar nilai tegangan dan regangan yang dihasilkan semakin tinggi.
\end{abstract}

Kata kunci: perkerasan semi-fleksibel, ziolit alam, reologi aspal, tegangan dan regangan, beban dinamis

\begin{abstract}
The resistance of the pavement structure due to the consequence of stress and strain causes the initial reset when the occurrence of permanent deformation so that pavement failure due to age is avoided. This phenomenon can be reduced by a pavement that has sufficient stiffness and flexibility. Material modification is carried out to increase the value of the stiffness and flexibility of the mixture by using the right type of mixture, gradation, and asphalt modification as an effort to develop an asphalt pavement mixture. The purpose of this study was to study the stress and tensile strain of the semi-flexible pavement (SFP) mixture against repeated loads with
\end{abstract}

Tegangan dan Regangan Dinamis Perkerasan Semi Fleksibel Dengan Modifikasi 


\begin{abstract}
the addition of rubber tire waste (WTR) and to use natural zeolite as a part of cement for mortar injected into the porous asphalt cavity. The design of a porous asphalt mixture begins with the determination of the optimal proportion of asphalt with an open grade aggregate specified in the Asphalt Pavement Association Australia (AAPA) 2004.Marshall test is carried out to see the required specifications and test specimens that have been injected with cement with a four-point loading bending method test for stress evaluation and tensile strain. The values of dynamic stress and strain were analyzed for each variation of ziolite in cement mortar. Substitution of natural ziolite in cement mortar can affect the dynamic stress and strain of the PSF mixture, where the greater the ziolite composition in cement mortar, the higher the resulting stress and strain.
\end{abstract}

Keywords: Pavement semi-flexible, natural zeolite, asphalt rheology, dynamic stress and strain

\title{
1. Latar Belakang
}

Tegangan dan regangan dinamis yang ditimbulkan oleh beban roda kendaraan mempunyai pengaruh yang besar terhadap kerusakan lapisan perkerasan jalan (Riyana et al., 2017). Untuk mengurangi resiko kerusakan prematur akibat timbulnya tegangan dan regangan yang berlebihan pada lapisan perkerasan aspal dilakukan berbagai upaya salah satu perbaikan sifat fisis aspal sebagai bahan pengikat dan modifikasi campuran. Modifikasi material yang dilakukan meningkatkan nilai kekakuan dan kelenturan campuran dengan jenis campuran, gradasi, dan modifikasi aspal yang tepat sebagai usaha pengembangan campuran beraspal (Casey et al., 2008).

Modifikasi jenis campuran merupakan penggabungan antara perkerasan fleksibel dengan perkerasan kaku yang dinamakan perkerasans semi fleksibel (PSF). Perkerasan semi fleksibel (PSF) dibuat dengan campuran aspal matriks bergradasi terbuka (rasio void 20-30\%) dan mengisinya dengan mortar semen yang terseleksi (Suresha, Varghese and Shankar, 2009). Pengikat aspal harus mampu menahan tekanan termal karena perubahan suhu dan penyusutan perkerasan yang dihasilkan untuk menahan beban lalu lintas tanpa timbul keletihan akibat proses pemuatan dan pembongkaran berulang dan menahan deformasi permanen akibat lalu lintas berat (Zhang et al., 2014).

Perilaku tegangan dan regangan tersebut regangan tarik paling dominan pengaruhnya terhadap kinerja perkerasan, sehingga terjadinya retak yang merupakan awal kegagalan lapisan perkerasan. Ketahanan campuran beraspal akibat kegagalan struktur lapisan perkerasan berupa kerusakan kelelahan dapat diperkirakan dengan pengujian dibebani secara berulang (Said et al., 2011). Pengujian umur kelelahan menggunakan metode pengujian lentur salah satu metode yang paling disukai karena selain penyebaran tegangan yang seragam juga lebih mensimulaikan kondisi campuran beraspal sebenarnya di lapangan (Harvey et al., 2003). Pembebanan dilakukan dengan tiga titik atau empat titik dan dilakukan pada kondisi kontrol tegangan atau kontrol regangan. Kondisi kontrol tegangan, beban yang diberikan konstan, besarnya lendutan yang terjadi merupakan nilai yang diukur (R. A. Yamin dan I. Aschuri, 2002).

Tegangan dan Regangan Dinamis Perkerasan Semi Fleksibel Dengan Modifikasi Reologi Aspal dan Substitusi Ziolit Pada Semen Mortar - Hamzani, Munirwansyah, Sugiarto, Muttaqin Hasan 
Beberapa tahun terakhir, penggunaan waste tire rubber (WTR) sebagai bahan tambah aspal sudah sangat luas diteliti, namun referensi sebagai model desain terhadap campuran beraspal dengan WTR sebagai bahan tambah dan variasinya dengan pengujian tegangan dan regangan dinamis masih terbatas. Banyak aspek WTR pada sifat-sifat campuran aspal dipelajari seperti daya tahan, stabilitas dan ketahanan terhadap kerusakan dan sebagainya, namun yang paling penting, keberadaan WTR dapat secara signifikan meningkatkan sifat fisik campuran aspal (Deshmukh and Kshirsagar, 2017), (Zhang et al., 2016), (Kim and Lee, 2015). Namun, efek WTR dengan ziolit alam sebagai substitusi parsial untuk mortar cemen di campuran aspal berpori belum sepenuhnya dipahami. Lebih lanjut, penelitian dan literatur yang sangat terbatas dapat ditemukan di mana efek ziolit alam sebagai substitusi semen mortar terhadap tegangan dan regangan maupun kinerja campuran perkerasan semi fleksibel (PSF) telah dilaporkan.

Mortar semen sebagai bahan pengisi rongga yang digunakan untuk pembuatan PSF dengan cara menginjeksi ke dalam rongga membuat aspal porous menjadi lebih kaku (Ge et al., 2016). Komposisi mortar semen yang tepat untuk dapat mengisi void in the mix (VIM) dari campuran aspal porous bisa menghasilkan campuran yang baik serta memberikan kekuatan maksimum (Plug et al., 2006). Mortar semen yang digunakan harus memiliki viskositas rendah yang mendekati viskositas air, tidak menyusut dan memiliki kekuatan yang memadai (Yamin and Siswosubrotho, 2002). Modifikasi bahan pengikat motar semen dilakukan untuk mendapatkan mortar berkulitas sehingga nilai kekakuan dan stabilitas dapat mempengaruhi kinerja PSF meningkat pula.

Tujuan dari penelitian ini untuk mempelajari pengaruh reologi aspal dan substitusi ziolit dalam mortar semen terhadap kinerja tegangan dan regangan dinamis campuran perkerasan semi-fleksibel (PSF). Selain itu untuk mengetahui proporsi optimum ziolit alam sebagai pengganti sebagian semen mortar yang dapat meningkatkan kinerja campuran PSF berdasarkan parameter tegangan dan reganagan dinamis. Pada penelitian ini material WTR 5\% yang digunakan merupakan komposisi optimum dari hasil penelitian sebelumnya tentang pengujian kuat tekan dan lentur (Hamzani et al., 2019).

\section{Metode Penelitian}

\subsection{Material}

PSF dirancang dari campuran aspal porous dengan rongga (20-30)\% dan diisi mortar semen sebagai usaha meningkatkan kekakuan campuran. Campuran aspal porus yang digunakan dalam penelitian ini berpedoman pada spesifikasi Asphalt Pavement Assosiation, (AAPA, 2004) (2004 Anonim, 2004), dengan kadar rongga $18-25 \%$. Material aspal porous terdiri agregat kasar, agregat halus, aspal dan parutan ban bekas, semen, ziolit alam, dan air. Penggunaan ziolit alam menggantikan sebagian semen sebagai modifikasi untuk meningkatkan mutu mortar semen pada campuran PSF.

Agregat kasar berupa batu becah bergradasi terbuka dengan ukuran butir maksimum $19 \mathrm{~mm}$ sesuai dengan spesifikasi AAPA, 2004 (Anonim, 2004). Sebagai agregat halus digunakan pasir sungai dengan diameter maksimum 4,75 mm. Sifat fisis agregat kasar dan agregat halus diperlihatkan pada Tabel 1, sedangkan gradasi agregat campuran diperlihatkan pada Gambar 1.

Tegangan dan Regangan Dinamis Perkerasan Semi Fleksibel Dengan Modifikasi Reologi Aspal dan Substitusi Ziolit Pada Semen Mortar - Hamzani, Munirwansyah, Sugiarto, Muttaqin Hasan 
Tabel 1 Sifat fisis agregat kasar dan agregat halus

\begin{tabular}{lcc}
\hline \multicolumn{1}{c}{ Sifat fisis } & Agregat kasar & Agregat kasar \\
\hline Berat jenis bulk $\left(\mathrm{gr} / \mathrm{cm}^{3}\right)$ & 2,340 & 2,521 \\
\hline Berat jenis semu $\left(\mathrm{gr} / \mathrm{cm}^{3}\right)$ & 2,467 & 2,598 \\
\hline Penyerapan air $(\%)$ & 1,937 & 1,890 \\
\hline
\end{tabular}

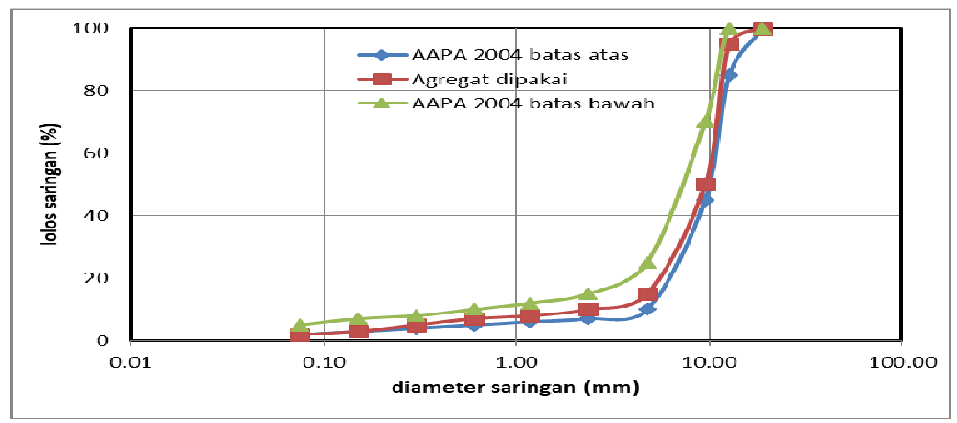

Gambar 1 Gradasi agregat rancangan campuran

Bahan pengikat aspal yang digunakan aspal penetrasi 60/70 buatan PT Pertamina dengan berat jenis lebih besar $1 \mathrm{gram} / \mathrm{cm}^{3}$, titik lembek lebih besar 48 ${ }^{\circ} \mathrm{C}$, titik nyala $232^{\circ} \mathrm{C}$. WTR yang digunakan adalah yang tersedia di pasaran berupa parutan ban bekas dengan ukuran lolos saringan no. 3/8 (9,52 mm). Semen yang digunakan adalah semen Portland tipe II buatan PT Semen Andalas Indonesia dengan berat jenis $3,16 \mathrm{gr} / \mathrm{cm}^{3}$.

Tabel 2 Komposisi senyawa kimia zeolit alam

\begin{tabular}{cc}
\hline Oksida & Persen (\%) \\
\hline $\mathrm{S}_{\mathrm{i}} \mathrm{O}_{2}$ & 46,57 \\
\hline $\mathrm{Al}_{2} \mathrm{O}_{3}$ & 16,58 \\
\hline $\mathrm{Fe}_{2} \mathrm{O}_{3}$ & 10,21 \\
\hline $\mathrm{CaO}$ & 8,77 \\
\hline $\mathrm{MgO}$ & 4,81 \\
\hline $\mathrm{Na}_{2} \mathrm{O}_{3}$ & 2,97 \\
\hline $\mathrm{K}_{2} \mathrm{O}$ & 0,87 \\
\hline $\mathrm{MnO}_{\mathrm{TiO}}$ & 0,14 \\
\hline $\mathrm{P}_{2} \mathrm{O}_{5}$ & 0,83 \\
\hline Kihilangan pijar & 0,14 \\
\hline
\end{tabular}

Ziolit yang digunakan adalah ziolit alam yang berasal dari Desa Ujong Pancu, Kabupaten Aceh Besar, Indonesia. Penggunaan ziolit melalui proses penghalusan dan diayak untuk memenuhi spesifikasi yang lolos saringan no. 200,

Tegangan dan Regangan Dinamis Perkerasan Semi Fleksibel Dengan Modifikasi Reologi Aspal dan Substitusi Ziolit Pada Semen Mortar - Hamzani, Munirwansyah, Sugiarto, Muttaqin Hasan 
selanjutnya bubuk diaktivasi dengan menggunakan asam klorida $(\mathrm{HCl}) 30 \%$ dan dicuci dengan aqua demineral untuk membersihkan kotoran-kotoran yang ada. Sebelum digunakan, bubuk ziolit dikeringkan dahulu pada suhu kamar.

Komposisi kimia bubuk ziolit teraktivasi diperiksa dengan $X$-ray fluorescence test (XRF), dan hasil pengujian untuk mengetahui senyawa kimia dan ukuran butiran partikel ziolit alam Aceh teraktivasi. Komposisi kimia dan ukuran partikel tersebut sangat berpengaruh terhadap kinerja material terutama unsur kimia $\mathrm{S}_{\mathrm{i}} \mathrm{O}_{2}$ dan $\mathrm{Al}_{2} \mathrm{O}_{3}$ yang merupakan silika dan alumina dengan kandungan masing-masing 46,57\% dan 16,58\%. Komposisi kimia dan kandungan unsur material ziolit disajikan pada Tabel 2.

\subsection{Penentuan kadar aspal optimum (KAO)}

Penentuan kadar aspal optimum (KAO) menggunakan metode AAPA (2004). Untuk mendapatkan KAO melalui pengujian Marshall menggunakan benda uji silinder berdiameter $102 \mathrm{~mm}$ dan tinggi $64 \mathrm{~mm}$ dengan kadar aspal 3\%, $3.5 \%, 4 \%, 4.5 \%$ dan 5\%. Untuk setiap kadar aspal dibuat 3 buah benda uji pada setiap variasi aspal. Pada pengujian ini aspal sebagai bahan pengikat agregat digunakan aspal penetrasi 60/70. Pengujian Marshall dilakukan berdasarkan ASTM C670-91a, dan hasil pengujian yang digunakan berupa nilai rata-rata pada setiap variasi aspal beserta persyaratan AAPA (2004) diperlihatkan pada Tabel 3. Berdasarkan data tersebut diperoleh nilai $\mathrm{KAO}$ sebesar 3.5\% seperti diperlihatkan pada Tabel 3.

Tabel 3 Hasil pengujian Marshal untuk penentuan KAO

\begin{tabular}{|c|c|c|c|c|c|c|}
\hline \multirow{2}{*}{ Parameter Marshall } & \multicolumn{5}{|c|}{ Kadar aspal (\%) } & \multirow{2}{*}{$\begin{array}{c}\text { Spesifikasi } \\
\text { AAPA } \\
(2004)\end{array}$} \\
\hline & 3.0 & 3.5 & 4.0 & 4.5 & 5.0 & \\
\hline Stability $(\mathrm{kg})$ & 503 & 512 & 470 & 362 & 356 & $\geq 500$ \\
\hline Flow $(\mathrm{mm})$ & 3,97 & 5,60 & 4.00 & 5,78 & 5,53 & $2-6$ \\
\hline $\begin{array}{l}\text { Void in the mix, VIM } \\
(\%)\end{array}$ & 24,95 & 24,70 & 22,64 & 18,43 & 13,88 & $18-25$ \\
\hline
\end{tabular}

Hasil pengujian Marshall campuran aspal porus yang memenuhi spesifikasi AAPA, 2004 pada komposisi aspal 3,5\%, dimana komposisi ini merupakan kadar aspal optimum.

\subsection{Pembuatan benda uji aspal porus}

Benda uji aspal porus dibuat dengan kadar aspal sebesar KAO yang diperoleh sebelumnya, yaitu 3,5\%. Aspal panas ditambahkan serbuk WTR sebanyak 3\%, 4\% dan 5\% dari berat aspal sehingga didapat tiga jenis campuran yang berbeda. Agregat yang sudah disiapkan dipanaskan pada suhu $170{ }^{\circ} \mathrm{C}$. Begitu juga dengan aspal dipanaskan pada suhu $160{ }^{\circ} \mathrm{C}$. Sesudah temperatur aspal mencapai $160{ }^{\circ} \mathrm{C}$, parutan WTR sesuai dengan kadar yang direncanakan ditambahkan ke dalam aspal panas dan diaduk merata serta pemanasan tetap dilanjutkan selama 5 menit. Agregat yang sudah panas tadi dimasukkan ke dalam campuran aspal diaduk selama lebih kurang 15 menit dengan pemanasan tetap

Tegangan dan Regangan Dinamis Perkerasan Semi Fleksibel Dengan Modifikasi Reologi Aspal dan Substitusi Ziolit Pada Semen Mortar - Hamzani, Munirwansyah, Sugiarto, Muttaqin Hasan 
dilanjutkan. Campuran tersebut dalam keadaan panas dimasukkan ke dalam cetakan yang telah disediakan dan dilakukan pemadatan pada saat suhu $140{ }^{\circ} \mathrm{C}$.

Pada umur benda uji berumur tiga hari, mortar diisi ke dalam rongga spesimen aspal porus dan dikeringkan pada suhu kamar selama 14 hari. Mortar yang digunakan adalah semen, pasir halus dan air yang diaduk secara merata. Perbandingan semen dan pasir halus adalah 1:2 berdasarkan perbandingan volume. Air digunakan secukupnya sehingga campuran tidak terlalu kental dengan melakukan pengujian fluidity digunakan alat uji hydraulic mortar sehingga memenuhi persyaratan Road Engineering Association of Malaysia (REAM) dengan waktu alir melalui corong alat uji selama 5 sampai 10 detik. Pengujian mortar semen dibuat empat variasi yang berbeda, yaitu dengan cara mensubstitusi semen dengan bubuk ziolit alam yang telah diaktivasi dengan variasi masingmasing $0 \%, 5 \%, 15 \%$ dan $25 \%$ dari berat semen. Pengisian mortar ke dalam spesimen aspal porous dilakukan dengan cara memasukkan mortar ke dalam wadah dan bersama specimen porous digetarkan dengan menggunakan alat penggetar mortar portable sehingga mortar masuk ke dalam rongga benda uji. Untuk setiap kadar ziolit yang berbeda diperoleh tiga buah benda uji SPF untuk dilakukan pengujian. Perawatan benda uji SPF dengan meletakkan benda uji secara terbuka di dalam ruangan pada suhu kamar.

Benda uji dirancang sedemikian rupa dengan ukuran cetakan $30 \mathrm{~cm}$ x $30 \mathrm{~cm}$ x $5 \mathrm{~cm}$, dan proses pemadatan dilakukan menggunakan pemadat sebesar 6,4 \pm $0,15 \mathrm{~kg} / \mathrm{cm} 2$. Pemberian beban sebesar nilai tersebut setara dengan beban sumbu tunggal roda ganda 8,16 ton (Japan Road Association, 1998). Untuk mendapatkan benda uji sesuai yang diharapkan, contoh sampel uji yang sudah padat dan berumur 14 hari dipotong menggunakan mesin potong gerinda sehingga ukuran benda uji menjadi $35 \mathrm{~cm}$ x $5 \mathrm{~cm} \times 5 \mathrm{~cm}$.

\section{Hasil dan Pembahasan}

\subsection{Tegangan tarik campuran PSF}

Besarnya tegangn tarik yang terjadi sangat tergantung pada kadar aspal dan kekakuan campuran beraspal. Pada penelitian ini kadar aspal digunakan sebesar 3,5\% merupakan kadar aspal optimum. Berdasarkan pengujian beban lentur menggunakan alat uji Dartec dengan standar AASTHO-T321-14 sistem empat titik pada benda uji campuran SFP berbentuk balok ukuran $35 \mathrm{~cm}$ x $5 \mathrm{~cm}$ x $6,5 \mathrm{~cm}$ dengan umur benda uji 14 hari diperoleh nilai tegangan tarik pada setiap variasi ziolit. Dari hasil tersebut bahwa nilai tegangan tarik yang didapat sangat bervariasi pada setiap variasi ziolit, dan nilainya tegangannya terus meningkat seiring jumlah siklus roda bertambah, namun pada batas tertentu mengalami penurunan yang signifikan. Titik penurunan yang signifikan tersebut merupakan batas tahapan kehancuran/keruntuhan campuran perkerasan PSF. Untuk analisis tegangan tarik pada setiap variasi ziolit campuran PSF dibuat grafik hubungan antara jumlah siklus roda dengan besarnya tegangan dinamis yang terjadi seperti diperlihatkan pada Gambar 2.

Berdasarkan hasil yang diperlihatkan pada Gambar 2 menunjukkan bahwa bentuk garis tegangan lentur/tarik yang terjadi mengalami tiga tahapan kondisi, yaitu kondisi elastis sempurna, kondisi semi elastis (mulai retak kecil), dan kondisi daerah keruntuhan. Tahapan elastis sempurna dimana pada kondisi tersebut campuran mengalami lendutan

Tegangan dan Regangan Dinamis Perkerasan Semi Fleksibel Dengan Modifikasi Reologi Aspal dan Substitusi Ziolit Pada Semen Mortar - Hamzani, Munirwansyah, Sugiarto, Muttaqin Hasan 
namun belum terjadi retak, selanjutnya tahapan semi elastis pada kondisi ini mulai timbul retak kecil di bagian bawah specimen dan retak tersebut merus menyebar dan membesar namus ketahanan dalam menahan beban sudah mulai menurun, sedangkan tahapan ketiga yaitu daerah runtuh dimana pada kondisi ini retak sudah terus membersar sampai terjadi patah.

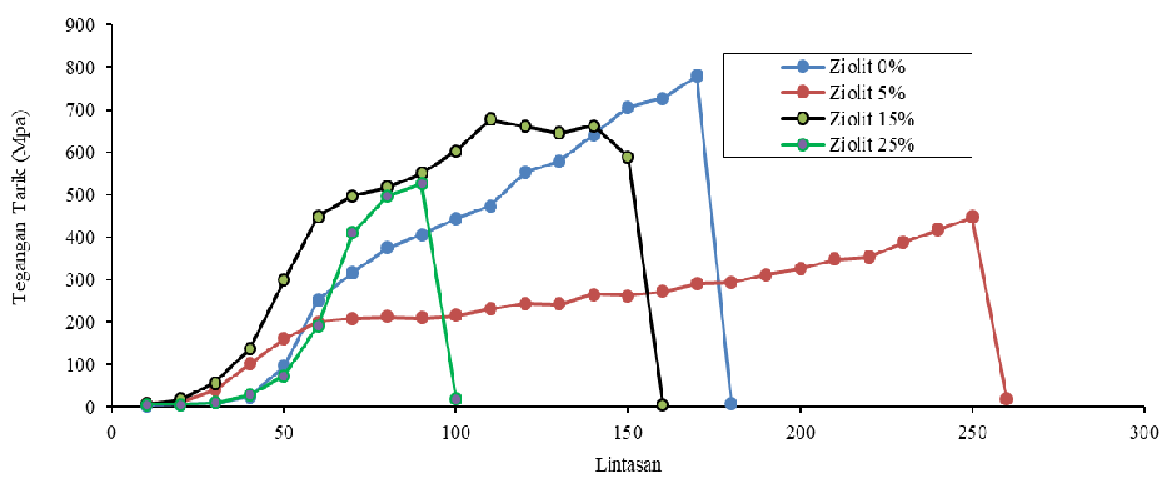

Gambar 2 Hubungan tegangan tarik dengan jumlah lintasan roda

Dari kondisi tersebut dapat dijelaskan bahwa penggantian ziolit semen mortar dengan bertambah variasi ziolit nilai tegangan tarik menjadi meningkat, namun ketahanan terhadap jumlah siklus roda menjadi berkurang. Dan dapat dinyatakan bahwa semakin tinggi nilai tegangan tarik yang dihasilkan oleh campuran PSF tetapi umur kelelahan campuran menjadi lebih pendek berdasarkan jumlah siklus roda kendaraan. Berdasarkan hasil pada Gambar 2 dan kenyataan tersebut dapat dinyatakan bahwa kinerja campuran PSF yang baik adalah terjadi pada substitusi ziolit 15\%, dimana pada kondisi tersebut bentuk elastisitas campuran relatih tinggi.

\subsection{Regangan tarik campuran PSF}

Berdasarkan pengujian regangan tarik pada specimen PSF menggunakan alat uji Dartec dengan standar AASTHO-T321-14 sistem empat titik pada benda uji campuran SFP berbentuk balok ukuran $35 \mathrm{~cm}$ x $5 \mathrm{~cm}$ x $6,5 \mathrm{~cm}$ diperoleh nilai regangan tarik pada setiap variasi ziolit. Nilai regangan tarik yang diperoleh juga mengalami perbedaan pada setiap variasi ziolit yang diberikan. Dari hasil tersebut bahwa setiap kenaikan variasi ziolit nilainya regangan terus meningkat seiring jumlah siklus roda bertambah, namun pada batas tertentu regangan mengalami penurunan yang signifikan. Titik penurunan yang signifikan tersebut merupakan batas tahapan kehancuran/keruntuhan campuran perkerasan PSF. Untuk lebih jelas kondisi regangan tarik pada setiap variasi ziolit campuran PSF diperlihatkan pada Gambar 3.

Berdasarkan hasil yang diperlihatkan pada Gambar 3 menunjukkan bahwa bentuk garis regangan lentur/tarik yang terjadi mengalami perbedaan pada setiap variasai ziolit campuran PSF. Dari bentuk garis regangan tarik tersebut dapat dilihat bahwa penggantian ziolit semen mortar semakin tinggi kadar ziolit, nilai regangan tarik yang dihasilkan menjadi meningkat, namun ketahanan terhadap jumlah siklus roda menjadi berkurang. Hal ini dapat dijelaskan semakin tinggi kadar ziolit dalam mortar semen kekakuan

Tegangan dan Regangan Dinamis Perkerasan Semi Fleksibel Dengan Modifikasi 
campuran PSF menjadi naik, sehingga berpengaruh terhadap ketahanan campuran PSF dalam menahan regangan dinamis menjadi rendah.

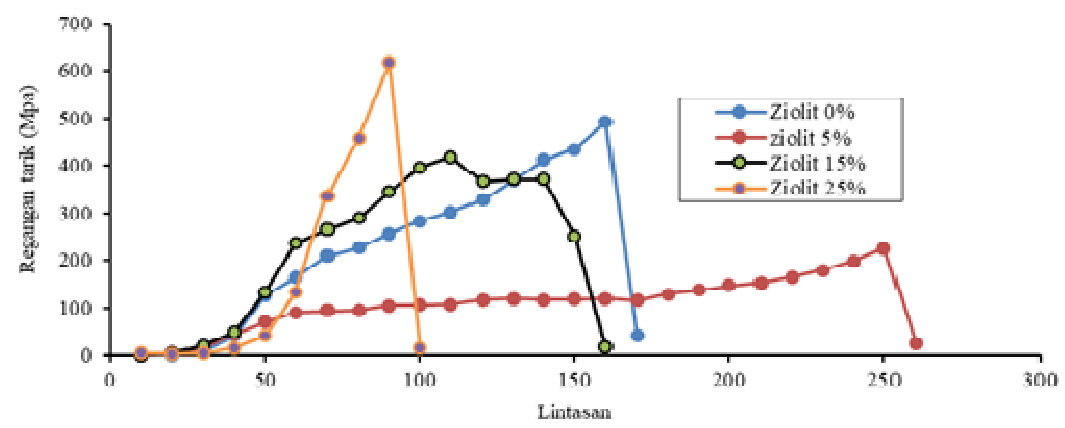

Gambar 3. Hubungan regangan tarik dengan jumlah lintasan roda

Nilai kinerja campuran PSF berdasarkan regangan dinamis yang paling baik diperoleh pada komposisi ziolit 15\%, dimana pada kondisi tersebut campuran mengalami diperoleh nilai elastisitas yang tinggi dan keruntuhan yang baik.

\section{Kesimpulan dan Saran}

\subsection{Kesimpulan}

Berdasarkan dari hasil penelitian dan pembahasan ini dapat diambil beberapa kesimpulan sebagai berikut:

1. Ziolit alam dapat digunakan untuk mengganti sebagian semen mortar untuk mengisi rongga dalam campuran aspal porus sehingga dapat meningkatkan kinerja campuran PSF.

2. Berdasarkan nilai tegangan dan regangan dinamis bahwa substitusi ziolit alam dalam semen mortar dapat mempengaruhi nilai tegangan dan regangan dinamis, namun ketahanan terhadap umur kelelahan/keruntuhan menjadi rendah, dan campuran dengan tingkat kekakuan yang tinggi dapat lebih mudah mengalami kelelahan dibandingkan dengan campuran yang kekakuannya lebih rendah, serta komposisi substitusi ziolit 15\% dalam semen mortar meupakan kinerja yang paling baik campuaran PSF berdasarkan uji tegangan dan regangan dinamis..

\subsection{Saran}

Untuk dapat diaplikasikan hasil penelitian ini terutama untuk perkerasan lalulintas sedang sampai tinggi diharapkan pada penelitian selanjutnya menggunakan material agregat lain dan aspal dengan peneterasi yang berbeda untuk mendapatkan nilai stabilitas lebih besar $500 \mathrm{~kg}$.

\section{Ucapan Terima Kasih}

Penelitian ini dilakukan dengan dana sendiri, penulis mengucapkan terima kasih kepada Sdr. M. Fadhil, Anas, Dik Waliandhi yang telah membantu kegiatan eksperimen ini untuk pengumpulan data.

Tegangan dan Regangan Dinamis Perkerasan Semi Fleksibel Dengan Modifikasi 


\section{Daftar Kepustakaan}

Anonim, 2004, Nasional Asphalt Spesifikation, Australia.

Anonim, 2004, AAPA_IG-8_Asphalt_Mix_Design.pdf, Australia.

Casey, D., Ciaran M. N., Amanda G., Gilchrist M.D., 2008, Development of a recycled polymer modified binder for use in stone mastic asphalt, Resources, Conservation and Recycling, 52(10), pp. 1167-1174.

Deshmukh, N. H. and Kshirsagar, P. D. Y., 2017, Utilization of Rubber Waste in Construction of Flexible Pavement, 2, pp. 70-77.

Ge, D., Yan K., You Z., Xu H., 2016, Modification mechanism of asphalt binder with waste tire rubber and recycled polyethylene, Construction and Building Materials. Elsevier Ltd, 126, pp. 66-76.

Hamzani, Munirwansyah, Hasan M., Sugiarto, 2019, The influence of the using waste tire rubber and natural ziolite as Asphalt and Cement replacements to compressive strength of Semi-Flexible Pavement, IOP Conference Series: Materials Science and Engineering, 523(1).

Harvey, J. T., Guada I., Hung D., Monismith C.L., 2003, Permanent Deformation And Fatigue Evaluation Of Asphalt Concrete Mixes, 6th RILEM Symposium PTEBM'03, Zurich, 2003, pp. 565-572.

Kim H. H. and Lee S. J., 2015, Effect of crumb rubber on viscosity of rubberized asphalt binders containing wax additives, Construction and Building Materials. Elsevier Ltd, 95, pp. 65-73.

Plug C. P., Bondt A.H., Van der Woerd B.J, Steensma G., 2006, Improved performance of grouted macadams - High Performance Applications of Grouted Macadam', Ooms Nederland Holding bv, (June).

R. A. Yamin dan I. Aschuri, 2002, Ketahanan fatig berbagai jenis campuran beraspal (gradasi spesifikasi baru dan lama), pp. 141-153.

Riyana, R. E., and Arung V. N., 2017, Analisis Tegangan, Regangan, Dan Deformasi Pada Perkerasan Lentur Porus Dan Konvensional Dengan Skala Semi Lapangan'.

Said, S.F., Hakim H., Carlsson H., Wiman L.G., 2011, Fatigue Life Evaluation of Flexible Pavement, International Journal of Pavement Research and Technology, 4(2), p. 80.

Suresha, S. N., Varghese, G. and Shankar, A. U. R., 2009, Characterization of porous friction course mixes for different Marshall compaction efforts, Construction and Building Materials. Elsevier Ltd, 23(8), pp. 2887-2893.

Yamin, R. A. and Siswosubrotho, B. I., 2002, Modifikasi Marshall Dalam Perencanaan Campuran Aspal Porus Untuk Cement Treated Asphalt Mixture (Ctam), 19 (23).

Tegangan dan Regangan Dinamis Perkerasan Semi Fleksibel Dengan Modifikasi Reologi Aspal dan Substitusi Ziolit Pada Semen Mortar - Hamzani, Munirwansyah, Sugiarto, Muttaqin Hasan 
Zhang, D., Huang, Zhao X., Zhang Y., Sulong, 2014, Rubberized asphalt mixture design using a theoretical model, Construction and Building Materials. Elsevier Ltd, 67, pp. 265-269..

Zhang, J., Cai J., Pei J., Li R., Chen X., 2016, Formulation and performance comparison of grouting materials for semi-flexible pavement, Construction and Building Materials. Elsevier Ltd, 115, pp. 582-592. 